\title{
(6) OPEN ACCESS \\ Low detection rate of advanced neoplasia within 5 years after polypectomy of small serrated adenoma
}

\author{
Duochen Jin, ${ }^{1}$ Hailong Cao, ${ }^{1}$ Bikash Kumar Shah, ${ }^{1}$ Danfeng Chen, ${ }^{1}$ Yujie Zhang, ${ }^{2}$ \\ Tianyu Liu, ${ }^{1}$ Wenxiao Dong, ${ }^{1}$ Sinan Wang, ${ }^{1}$ Yanrong Qi, ${ }^{3}$ Bangmao Wang ${ }^{1}$
}

'Department of

Gastroenterology and Hepatology, General Hospital,

Tianjin Medical University,

Tianjin, China

2Department of Pathology,

General Hospital, Tianjin Medical

University, Tianjin, China

${ }^{3}$ Department of

Gastroenterology and

Hepatology, Tianjin Binhai

People's Hospital, Tianjin, China

\section{Correspondence to}

Dr Hailong Cao, Department

of Gastroenterology and

Hepatology, General Hospital,

Tianjin Medical University,

Tianjin 300052, China;

caohailong@tmu.edu.cn

Received 3 December 2018 Revised 15 February 2019

Accepted 16 February 2019

Published Online First 29 March 2019

Check for updates

(C) Author(s) (or their employer(s)) 2019. Re-use permitted under CC BY-NC. No commercial re-use. See rights and permissions. Published by BMJ.

To cite: Jin D, Cao H, Shah BK, et al. Postgrad Med J 2019:95:187-192

\section{ABSTRACT}

Aim Patients with small serrated adenomas (SAs) $(<10 \mathrm{~mm}$ ) often undergo surveillance colonoscopy before the routine recommended time. We aimed to determine the appropriate surveillance intervals following polypectomy of small SAs for symptomatic patients. Method We retrospectively reviewed the data of 638 patients, including 122 cases and 516 controls. Subjects in the case group had small SAs at baseline colonoscopy, including sessile SA/polyps and traditional SAs, while subjects in the control group had negative findings. All patients underwent at least one surveillance colonoscopy during the following 5 years.

Results There was no significant difference in the incidence rate of advanced neoplasia between the two groups over a 5 -year duration $(3.6 \%$ vs $2.6 \%$, $\mathrm{p}=0.455)$. Moreover, both groups also showed a low prevalence of SA formation over $1-5$ years $(3.6 \%$ vs $1.0 \%, p=0.145)$. Patients with baseline SA tended to undergo the first surveillance colonoscopy earlier than those without adenoma ( $\leq 1$ year vs 1 to $\leq 3$ years). Seventy-one $(11.1 \%)$ of the total included subjects underwent inadequate initial colonoscopy, and 30 $(42.3 \%)$ underwent early surveillance of adenoma formation within 1 year. Patients with a family history of colorectal cancer (OR 4.69, 95\% Cl 1.48 to 14.71 , $\mathrm{p}=0.017$ ) or inadequate baseline colonoscopy (OR 3.17, $95 \% \mathrm{Cl} 1.202$ to $8.409, p=0.035$ ) were at a higher risk of metachronous adenoma formation during the surveillance period.

Conclusion Patients with small SAs at baseline gain little benefit from follow-up of colonoscopy within 5 years after complete polypectomy.

\section{INTRODUCTION}

The serrated pathway is recognised as a molecular pathway to colorectal cancer (CRC), which accounts for $20 \%-30 \%$ of the population overall. ${ }^{1}$ Unlike the chromosomal instability pathway ${ }^{2}$ and the Lynch pathway, ${ }^{3}$ which develop through conventional adenomas, serrated lesions, especially sessile serrated adenoma/polyps (SSA/Ps) and traditional serrated adenomas (TSAs) with excessive methylcytosine in $\mathrm{CpG}$ islands, have been considered as hypermethylated pathways, which may devitalise tumour suppressor genes. ${ }^{4-6}$ According to the WHO classification, serrated colorectal lesions can be divided pathologically into three subtypes: hyperplastic polyp (HP), SSA/P and TSA. ${ }^{7}$ The incidence of coexisting submucosal invasive carcinoma in patients with baseline HPs was reported as low as $0.1 \%,{ }^{8}$ so SSA/P and TSA require more attention than HP due to the higher malignant potential.

Endoscopic resection and endoscopic mucosal resection (EMR) contribute to en bloc resection of small serrated lesions $(<10 \mathrm{~mm})$ and have been widely used in the clinic for their feasibility and safety. ${ }^{9-11}$ However, patients with a proximal serrated lesion were still at much greater risk of colorectal neoplasia in a follow-up study due to the absence of surveillance for serrated polyps after resection. ${ }^{12}$ The serrated pathway is associated with interval cancers during the following 5 years after colonoscopy. ${ }^{13}$ Moreover, residual neoplasia of serrated polyps after colonoscopic polypectomy is inevitable, and complete resection becomes increasingly difficult as the size of the lesion increases. ${ }^{114} 15$ A systematic review and meta-analysis published between January 2006 and July 2015 summarised 11 observational studies $(n=64$ 317) and found that patients with low-risk adenomas were at higher risk of advanced adenomas compared with those with a normal baseline colonoscopy (risk ratio [RR] $1.55,95 \%$ CI 1.24 to $1.94, \mathrm{P}=0.0001) .{ }^{16}$ Hence, colonoscopy surveillance after complete resection of serrated polyps cannot be ignored.

After polypectomy, more than $75 \%$ of the patients did not meet the standard interval of endoscopic monitoring. ${ }^{17} 18$ There are various recommended guidelines for endoscopic surveillance intervals after the baseline colonoscopy. Under general consideration, serrated polyps $\geq 10 \mathrm{~mm}$ or any serrated lesions with dysplasia necessitate post-polypectomy colonoscopy surveillance at an interval of 3 years. Patients with serrated polyps $<10 \mathrm{~mm}$ without any dysplastic changes are advised to prolong the follow-up interval from 5 years to 10 years. ${ }^{7}{ }^{19-22}$ Moreover, the British Society of Gastroenterology has suggested that regardless of the pathological pattern, no endoscopic surveillance is advised when all serrated polyps are smaller than $10 \mathrm{~mm}$ without any dysplastic progression except serrated polyposis syndrome. ${ }^{23}$ Interestingly, according to the latest research update, patients with index SSA/Ps or TSAs are at high risk of large metachronous serrated polyps (RR 9.70, 95\% CI 3.63 to 25.92 ) but not metachronous high-risk adenomas. ${ }^{24}$ Nevertheless, due to the lack of data in the Asia-Pacific region, these criteria might not be the standard guideline for follow-up in these areas owing to ethnic differences. ${ }^{25}$ Hence, we compared the incidence of advanced neoplasia (AN) in the following 5 years of observation between patients with $<10 \mathrm{~mm}$ SAs and those without adenoma at 
baseline during the same period. This study aimed to investigate an appropriate surveillance interval for SA $<10 \mathrm{~mm}$ and to identify risk factors related to subsequent $\mathrm{AN}$ formation.

\section{METHODS}

\section{Study population}

Consecutive patients were enrolled in this single-centre retrospective study. Patients enrolled in the study underwent colonoscopies from January 2010 to July 2017 at the Digestive Endoscopy Center of the General Hospital, Tianjin Medical University. Patients with SAs from $1 \mathrm{~mm}$ to $9 \mathrm{~mm}$ and those without any adenoma (hyperplastic polyp or no polyp) at routine baseline observation were recruited as a study population if they had undergone at least one or more follow-up colonoscopy surveillance visit within 5 years of the study. All SAs found at baseline were completely removed by biopsy forceps (for diminutive polyps 1-4 mm) or EMR or electrocautery (for larger ones 5-9 $\mathrm{mm}$ ). Follow-up data were recorded in the database, and those who chose colonoscopic surveillance at other hospitals were followed up via telephone. The surveillance intervals of the patients' follow-up were divided into three groups after polypectomy: follow-up $\leq 1$ year, 1 to $\leq 3$ years and 3 to $\leq 5$ years.

The following subjects were excluded: (1) patients with inflammatory bowel disease or intestinal tuberculosis; (2) patients with familiar hereditary polyposis syndromes, previous diagnosis of CRC or colon removal; (3) patients having a previous colonoscopy within 5 years before this baseline colonoscopy; (4) patients without complete follow-up data or pathological reports; (5) patients receiving complete polypectomy of SAs during the 3 months prior to study entry.

\section{Baseline colonoscopy review}

All colonoscopic examinations were performed by certified endoscopists, and the endoscope used was an Olympus CF-Q260 (Olympus Optical, Tokyo, Japan). The withdrawal duration of every endoscopy performed was at least 6 min. ${ }^{26}$ The general information of the patients was collected from the colonoscopy database (data from case history, colonoscopy report and pathology report), including (1) patients' gender, age and family history of CRC or personal history of polyps; (2) the indications for the initial colonoscopy; (3) the location, size, number and pathological classification of any polyps detected; and (4) the quality of the bowel preparation, which was assessed according to the Boston Bowel Preparation Scale ${ }^{27}$ as adequate or inadequate. We used the term 'serrated adenoma' to search the colonoscopy database and finally selected 122 cases with serrated adenomas $<10 \mathrm{~mm}$ in size. After that, we invited a senior pathologist to re-evaluate the diagnosis. If there was a dispute about the subtype of pathology, three pathologists jointly evaluated the final conclusion. The final diagnosis depended on the pathological outcome.

\section{First follow-up outcome}

We found that most of the subjects included in our study underwent the first follow-up colonoscopic examination due to comprehensive reasons, such as sustained gastrointestinal discomfort, fear of cancerous progression and physicians' recommendations. Several definitions were taken under consideration before analysing the surveillance outcomes. ${ }^{8} 28$ AN was defined as having adenomas $\geq 10 \mathrm{~mm}$, villous histology and high-grade dysplasia or carcinomas. Non-advanced adenomas (NAAs) were defined as having one or more tubular adenomas $<10 \mathrm{~mm}$. No adenomas were collectively defined as the presence of hyperplastic polyps or absence of any polyps. It has been reported that both SSAs and TSAs have excessive methylcytosine in CpG islands with malignant potential. ${ }^{29}{ }^{30}$ SSA/P and TSA were collectively referred to as serrated adenomas (SAs). If more than one polyp was detected during the follow-up colonoscopy, the stratification depended on the most advanced lesion found. The most advanced lesion was defined with the largest diameter or the most severe pathological pattern.

\section{STATISTICAL ANALYSIS}

Continuous variables with normal distribution were calculated as the mean $\pm \mathrm{SD}$, and variables with non-normal distribution were calculated as the median (IQR). Ratio and proportion were used to describe categorical data. The Kruskal-Wallis test followed by the Mann-Whitney U test was used to calculate non-normal data. Proportions were compared using Pearson's $\chi^{2}$ test or Fisher's exact probability test. Quantitative data were compared using Student's t-test. Risk factors for subsequent adenoma formation were presented as ORs with 95\% CIs. Statistical analyses were performed using SPSS V.17.0 software, and a two-tailed p value $<0.05$ was considered statistically significant.

\section{RESULTS}

\section{Patient characteristics at baseline}

Our colonoscopy database included 50033 colonoscopies performed from January 2010 to July 2017. During this period, 1137 patients underwent at least one follow-up colonoscopy within 5 years and met the research criteria described above. A total of 499 patients were excluded since they were found to have conventional adenomas at baseline. The number of patients included in our study was 638, including 122 patients $(19.1 \%)$ who had small SAs $(<10 \mathrm{~mm})$ and $516(80.9 \%)$ controls who had no adenoma (figure 1). A total of 587 cases of serrated lesions were retrieved from the database during the entire study period $(587 / 50033=1.17 \%)$. However, in our study, we focused on those with smaller sizes $(<10 \mathrm{~mm})$ and those who underwent surveillance colonoscopy in the following 5 years after complete removal. Moreover, patients whose integral information about case history, colonoscopy reports and pathology reports could not be tracked were excluded. Patients with hyperplastic polyps were also excluded. Finally, we included $20.8 \%$ individuals with serrated lesions in the current study (122/587).

The demographic and clinical characteristics of the study population are listed in table 1. A total of $37.7 \%$ (46/122) baseline SAs were found with low-grade dysplasia. In the whole cohort, $312(48.8 \%)$ were men, and the mean age of the total population

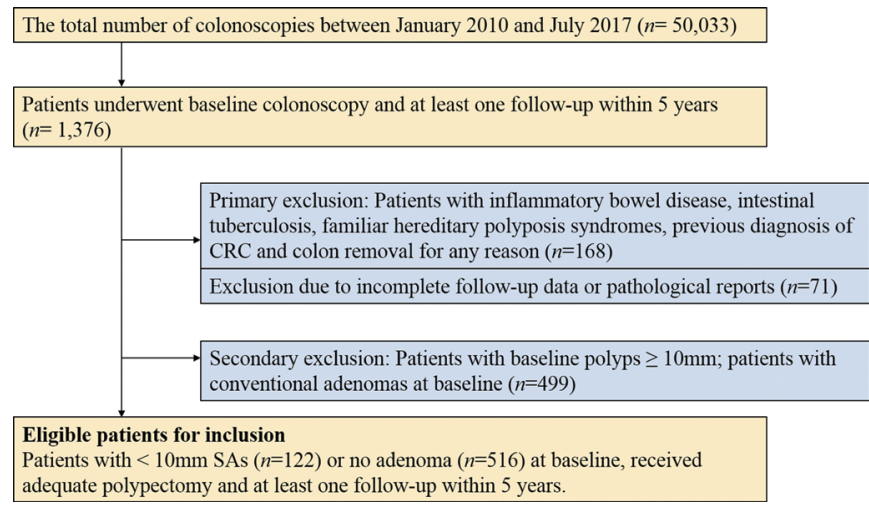

Figure 1 Inclusion and exclusion diagram of the study population. CRC, colorectal cancer; SA, serrated adenoma. 
Table 1 Baseline characteristics of the included subjects who underwent at least one follow-up colonoscopy within 5 years

\begin{tabular}{|c|c|c|c|c|}
\hline \multirow[b]{2}{*}{ Characteristics } & \multirow[b]{2}{*}{$\mathrm{n}(\%)$} & \multicolumn{3}{|c|}{ Period of time until the follow-up (years) } \\
\hline & & $\leq 1$ & 1 to $\leq 3$ & 3 to $\leq 5$ \\
\hline Total, n (\%) & $638(100)$ & $163(25.5)$ & $328(51.4)$ & $147(23.0)$ \\
\hline \multicolumn{5}{|l|}{ Sex } \\
\hline Male, $n(\%)$ & $312(48.9)$ & $94(30.1)$ & $159(51.0)$ & $59(18.9)$ \\
\hline Female, $\mathrm{n}(\%)$ & $326(51.1)$ & $69(21.2)$ & $169(51.8)$ & $88(27.0)$ \\
\hline Mean age at baseline colonoscopy (years), mean \pm SD & $53.2 \pm 12.6$ & $53.8 \pm 13.0$ & $53.7 \pm 12.7$ & $51.7 \pm 12.0$ \\
\hline \multicolumn{5}{|l|}{ Reasons for baseline colonoscopy, $\mathrm{n}(\%)^{*}$} \\
\hline Screening colonoscopy & $135(21.2)$ & $135(21.2)$ & $64(47.4)$ & $64(47.4)$ \\
\hline Family history of CRC & $16(2.5)$ & $3(18.8)$ & $10(62.5)$ & $3(18.8)$ \\
\hline Previous diagnosis of polyps & $87(13.6)$ & $35(40.2)$ & $36(41.4)$ & $16(18.4)$ \\
\hline Positive FOBT, bleeding or anaemia & $85(13.3)$ & $25(29.4)$ & $45(52.9)$ & $15(17.6)$ \\
\hline Diarrhoea or/and constipation & $179(28.1)$ & $42(23.5)$ & $102(57.0)$ & 35 (19.6) \\
\hline Other gastrointestinal symptoms $\dagger$ & $323(50.6)$ & $82(25.4)$ & $152(47.1)$ & 89 (27.6) \\
\hline \multicolumn{5}{|l|}{ Baseline colonoscopy quality, n (\%) } \\
\hline Excellent preparation & $262(41.1)$ & $63(24.0)$ & $142(54.2)$ & $57(21.8)$ \\
\hline Good preparation & $223(35.0)$ & $43(19.3)$ & $125(56.1)$ & $55(24.7)$ \\
\hline Fair preparation & $93(14.6)$ & $31(33.3)$ & $41(44.1)$ & $21(22.6)$ \\
\hline Poor preparation & $60(9.4)$ & $26(43.3)$ & $20(33.3)$ & $14(23.3)$ \\
\hline Could not reach the caecum & $22(3.4)$ & $10(45.5)$ & $11(50.0)$ & $1(4.5)$ \\
\hline Poor preparation and could not reach the caecum & $11(1.7)$ & $6(54.5)$ & $4(36.4)$ & $1(9.1)$ \\
\hline
\end{tabular}

*Patients might have more than one indication.

tOther gastrointestinal symptoms include abdominal pain, distention or any other discomfort.

CRC, colorectal cancer; FOBT, faecal occult blood test.

was $53.2 \pm 12.6$ years. A total of $163(25.5 \%)$ subjects underwent follow-up colonoscopy within 1 year, 328 (51.4\%) within 1-3 years and 147 (23.0\%) within 3-5 years. Patients with one, two, and three or more SAs at the initial colonoscopy underwent surveillance colonoscopy after 13 (3-63), 12 (6-42) and 11 (6-28) months, respectively $(\mathrm{p}=0.809)$. There was no significant difference in the follow-up interval in patients with a single SA between 1-5 $\mathrm{mm}$ and 6-9 mm observed at baseline (12 [3-63] vs 10 [3-48], $\mathrm{p}=0.129$ ). Most of the baseline colonoscopies were performed to make a definitive diagnosis, including positive faecal occult blood test/lower gastrointestinal haemorrhage/anaemia (85 [13.3\%]), changes in bowel habit (diarrhoea or/and constipation) (179 [28.1\%]) and any other gastrointestinal symptoms (abdominal pain, distention and other abdominal discomfort) (323 [50.6\%]). Additionally, some patients underwent baseline colonoscopies as they had a positive family history of CRC (16 [2.5\%]), a previous finding of polyps (87 [13.6\%]) or routine cancer screening (135 [21.2\%]). Of the baseline colonoscopies, 71 (11.1\%) patients underwent inadequate examinations, including poor bowel preparation (60 [9.4\%]) and no caecum-reached operation (22 [3.4\%]). Of the total baseline colonoscopies performed, $71(11.2 \%)$ patients had insufficient visualisation of the gastrointestinal tract due to poor bowel preparation (60 [9.4\%]) or an incomplete procedure due to the difficulty of the colonoscope in reaching the caecum (22 [3.4\%]).

\section{Colonoscopic and pathological findings at baseline and follow-up}

Of the 638 individuals, $171(26.8 \%)$ had metachronous adenomas, among which 22 (3.4\%) had AN, 139 (21.8\%) had NAA and $10(1.6 \%)$ had SA during the follow-up period, and the median follow-up time was 22 months (figure 2). Although none of the baseline adenomas were ever found in the control group, the number of patients with at least one follow-up adenoma was 119/516 (23.1\%). Among them, 16 (3.1\%) had AN (two of them were detected as high-grade intraepithelial neoplasia, eight of them had tubular adenomas $\geq 10 \mathrm{~mm}$ and six of them had villous ingredients), 99 (19.2\%) had NAA and $4(0.8 \%)$ had SA. However, when taking only these detected baseline SAs into account, $42.6 \%(52 / 122)$ patients had adenoma formation at follow-up, of whom 6 (4.9\%) had AN (none of them were detected as high-grade intraepithelial neoplasia, half of them had tubular adenomas $\geq 10 \mathrm{~mm}$ and the other half had villous ingredients), 40 (32.8\%) had NAA and 6 (4.9\%) had SA. We found that NAAs ranged in size from 1 to $8 \mathrm{~mm}$, with $52.5 \%(21 / 40)$ associated with low-grade dysplasia. Nevertheless, there were no significant differences in the incidence of AN and SA during the 5 years of study between patients with baseline SA and without any baseline adenomas (AN, 3.6\% vs $2.6 \% \mathrm{p}=0.455$; SA, $3.6 \%$ vs $1.0 \% \mathrm{p}=0.145)$.

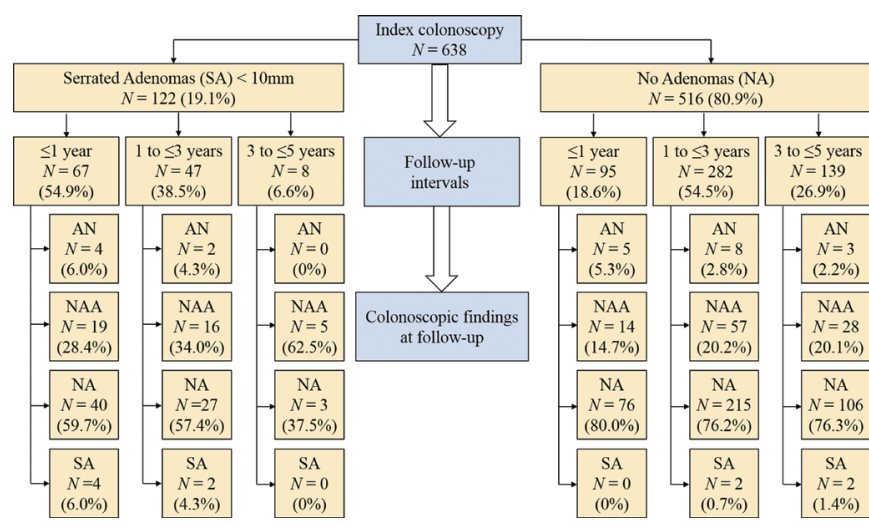

Figure 2 Endoscopic findings at baseline and follow-up colonoscopy in the included subjects. AN, advanced neoplasia; NA, no adenoma; NAA, non-advanced adenoma; $S A$, serrated adenoma including sessile serrated adenoma/polyp and traditional serrated adenoma. Both groups, even those with no adenomas at baseline, underwent follow-up colonoscopies within 5 years for comprehensive reasons. 
Table 2 Advanced neoplasia and serrated adenoma found at follow-up colonoscopy in included subjects

\begin{tabular}{lllllllll}
\hline & \multicolumn{1}{l}{ Follow-up AN } & \multicolumn{3}{l}{ Follow-up SA } \\
\hline Baseline & $\leq 1$ & 1 to $\leq 3$ & 3 to $\leq 5$ & P value* $^{*} \leq 1$ & 1 to $\leq 3$ & 3 to $\leq 5$ & P value* \\
Case group, $\mathrm{n}(\%)$ & $4(6.0)$ & $2(4.3)$ & $0(0.0)$ & 0.728 & $4(6.0)$ & $2(4.3)$ & $0(0.0)$ & 0.728 \\
Control group, $n(\%)$ & $5(5.3)$ & $8(2.8)$ & $3(2.2)$ & 0.481 & $0(0.0)$ & $2(0.7)$ & $2(1.4)$ & 0.402 \\
\hline
\end{tabular}

${ }^{*}$ Cohort $1-3$ years vs $3-5$ years.

AN, advanced neoplasia; SA, serrated adenoma.

Most of the patients (54.9\%) in the SA group underwent the first surveillance colonoscopy within 1 year. Meanwhile, those without any adenoma at baseline would delay their surveillance until 1 to 3 years later $(54.5 \%)$. In the whole population, the proportions of patients who had AN or SA at three intervals did not differ significantly. Nine patients $(5.6 \%)$ had AN within a 1-year interval, ten patients $(3.0 \%)$ had $\mathrm{AN}$ at $1-3$ years and three patients $(2.0 \%)$ had $A N$ at $3-5$ years $(p=0.202)$. The risks of SA at the three intervals were $2.5 \%, 1.2 \%$ and $1.4 \%$ at 1 year, $1-3$ years and $3-5$ years, respectively $(p=0.591)$. The risk of AN on the first surveillance colonoscopy was similar in the patients with intervals of $1-3$ years $(4.3 \%)$ and 3-5 years $(0.0 \%)$, which all had SA at baseline $(\mathrm{p}=0.728)$ (table 2$)$. SA also had a similar incidence in the two surveillance intervals $(4.3 \%$ vs $0.0 \%, p=0.728)$. Likewise, in the cohort without any baseline adenomas, different surveillance intervals (1-3 years and 3-5 years) did not significantly influence the risk of AN and SA detected at follow-up (AN at $1-3$ years and $3-5$ years, $2.8 \%$ vs $2.2 \%, \mathrm{p}=0.481$; SA at $1-3$ years and $3-5$ years, $0.7 \%$ vs $1.4 \%$, $\mathrm{p}=0.402$ ). Hence, after adequate polypectomy, patients with SA $<10 \mathrm{~mm}$ at baseline might not be at a greater risk for subsequent AN or SA formation within 5 years.

\section{Risk factors affecting subsequent adenoma formation}

A series of baseline characteristics that might influence follow-up adenoma formation are shown in table 3, which are presented as ORs with 95\% CIs. By analysing the whole population, age over 50 years (OR 1.45, 95\% CI 1.02 to 2.08), male gender
(OR $1.81,95 \%$ CI 1.27 to 2.58 ) and a history of polyps (OR $2.73,95 \%$ CI 1.71 to 4.34 ) predict the risk of any subsequent adenoma formation. Patients with a family history of CRC (OR $4.67,95 \%$ CI 1.48 to 14.71 ) were at greater risk for subsequent AN than those without. The case group was also independently assessed the metachronous adenoma formation according to adenoma features at baseline. Adenoma features, including the number, maximum diameter and location, did not significantly influence subsequent adenoma formation within 5 years.

\section{Quality of baseline colonoscopy associated with follow-up outcome}

Seventy-one (11.1\%) patients underwent inadequate baseline colonoscopies, including inadequate bowel preparation (60, $9.4 \%)$, and the operation did not reach the caecum $(22,3.4 \%)$. Nearly half of them $(30,42.3 \%)$ had received the initial surveillance colonoscopies within 1 year. Table 4 shows the relationship between the quality of colonoscopy at baseline and subsequent adenoma detection. The demographic characteristics, including age and gender, did not influence the completion of examination at the initial colonoscopy. Inadequate baseline colonoscopies contributed to a lower adenoma detection rate (ADR) compared with adequate examination at the initial colonoscopy $(16.9 \%$ vs $28.0, \mathrm{p}=0.046$ ). More $\mathrm{AN}$ and $\geq 3 \mathrm{NAA}$ could be found in patients with inadequate baseline colonoscopy than in those with adequate baseline examination $(8.5 \%$ vs $2.8 \%, \mathrm{p}=0.035$; $11.3 \%$ vs $4.4 \%, \mathrm{p}=0.014)$. Incomplete baseline colonoscopy

Table 3 Multivariate analyses for subsequent adenoma formation based on baseline characteristics in included subjects

\begin{tabular}{|c|c|c|c|c|c|c|c|}
\hline \multirow[b]{2}{*}{ Baseline } & \multirow[b]{2}{*}{ Total, $\mathbf{n}$} & \multicolumn{3}{|c|}{ Any adenoma in the follow-up } & \multicolumn{3}{|c|}{ AN in the follow-up } \\
\hline & & n (\%) & OR $(95 \% \mathrm{Cl})$ & $P$ value & n (\%) & OR $(95 \% \mathrm{Cl})$ & $P$ value \\
\hline \multicolumn{8}{|l|}{ Age (years) } \\
\hline Aged $\geq 50$ & 349 & $105(30.1)$ & 1.45 (1.02 to 2.08$)$ & 0.040 & $11(3.2)$ & 0.82 (0.35 to 1.93$)$ & 0.652 \\
\hline Aged $<50$ & 289 & $66(22.8)$ & & & $11(3.8)$ & & \\
\hline \multicolumn{8}{|l|}{ Sex } \\
\hline Male & 312 & $102(32.7)$ & 1.81 (1.27 to 2.58$)$ & 0.001 & $13(4.2)$ & 1.53 (0.65 to 3.64$)$ & 0.331 \\
\hline Female & 326 & $69(21.2)$ & & & $9(2.8)$ & & \\
\hline \multicolumn{8}{|l|}{ Family history of CRC } \\
\hline With & 32 & $12(37.5)$ & 1.60 (0.77 to 3.35$)$ & 0.206 & $4(12.5)$ & 4.67 (1.48 to 14.71$)$ & 0.017 \\
\hline Without & 606 & $159(26.2)$ & & & $18(3.0)$ & & \\
\hline \multicolumn{8}{|l|}{ History of polyps } \\
\hline With & 87 & $40(46.0)$ & 2.73 (1.71 to 4.34$)$ & $<0.001$ & $6(6.9)$ & $2.48(0.94$ to 6.51$)$ & 0.103 \\
\hline Without & 551 & $131(23.8)$ & & & $16(2.9)$ & & \\
\hline \multicolumn{8}{|l|}{ Adenoma features* } \\
\hline$\geq 2$ adenomas & 30 & $19(63.3)$ & 1.44 (0.67 to 3.10$)$ & 0.351 & $1(3.3)$ & 0.41 (0.05 to 3.64) & 0.707 \\
\hline One adenoma & 92 & $33(35.9)$ & & & $5(5.4)$ & & \\
\hline 6-9 mm adenoma & 41 & $19(46.3)$ & 1.26 (0.59 to 2.68$)$ & 0.555 & $4(9.8)$ & 4.27 (0.75 to 24.37$)$ & 0.189 \\
\hline$\leq 5 \mathrm{~mm}$ adenoma & 81 & $33(40.7)$ & & & $2(2.5)$ & & \\
\hline Distal adenoma & 73 & $36(49.3)$ & 2.01 (0.95 to 4.26$)$ & 0.068 & $3(4.1)$ & $0.66(0.13$ to 3.40$)$ & 0.939 \\
\hline Proximal adenoma & 49 & $16(32.7)$ & & & $3(6.1)$ & & \\
\hline
\end{tabular}

${ }^{*}$ Adenoma features were compared among patients with baseline SA.

AN, advanced neoplasia; CRC, colorectal cancer. 
Table 4 Comparison of the characteristics of the included subjects according to the quality of baseline colonoscopy

\begin{tabular}{llll}
\hline & \multicolumn{3}{l}{ Baseline colonoscopy } \\
\cline { 2 - 4 } & $\begin{array}{l}\text { Inadequate } \\
\text { examination }\end{array}$ & $\begin{array}{l}\text { Adequate } \\
\text { examination }\end{array}$ & \\
Characteristics, $\mathbf{n}(\%)$ & $\mathbf{7 1 ( 1 1 . 1 \% )}$ & $\mathbf{5 6 7}(\mathbf{8 8 . 9 \% )}$ & P value \\
\hline Aged $\geq 50$ & $35(49.3)$ & $314(55.4)$ & 0.340 \\
\hline Male & $37(52.1)$ & $275(48.5)$ & 0.566 \\
\hline ADR at baseline & $12(16.9)$ & $159(28.0)$ & $0.046^{*}$ \\
\hline Follow-up results & & & \\
\multicolumn{1}{l}{ AN } & $6(8.5)$ & $16(2.8)$ & $0.035^{*}$ \\
\hline SA & $2(2.8)$ & $8(1.4)$ & 0.369 \\
\hline 1-2 NAA & $8(11.3)$ & $25(4.4)$ & $0.014^{*}$ \\
\hline
\end{tabular}

*Significant difference between the group with inadequate baseline examination and those with an adequate one.

$A D R$, adenoma detection rate; $A N$, advanced neoplasia; NAA, non-advanced adenoma; $\mathrm{SA}$, serrated adenoma.

increased follow-up AN formation to a 3.17 OR risk (95\% CI 1.202 to 8.409 ). Taken together, these findings strongly suggest that patients with inadequate baseline colonoscopy should have a shorter surveillance interval.

\section{DISCUSSION}

A certain percentage of asymptomatic populations over 50 years have not undergone colonoscopy screening due to a lack of proper health awareness and financial crisis. On the other hand, frequent surveillance colonoscopy is suggested by physicians and endoscopists for low-risk patients, which possess considerable pressure due to limited available endoscopic resources. The current study, based on a representative Chinese cohort, assessed post-polypectomy colonoscopy surveillance of SAs $<10$ $\mathrm{mm}$ during the following 5 years. During this study, we found no significant risk differences between the baseline SAs and those without any adenoma after complete polypectomy in the progression of AN within 5 years. A shorter surveillance interval is needed for patients with a family history of CRC or inadequate baseline colonoscopy. In Asian countries, there are no specific guidelines for surveillance colonoscopy after polypectomy. The study discussed here is both important and interesting owing to its contribution to the establishment of guidelines for colonoscopy surveillance after polypectomy of small SSA/Ps or TSAs.

Serrated lesions play a crucial role in the carcinogenesis of the colon. ${ }^{31} 32$ The risk of CRC in patients with serrated polyps is strongly associated with the size of the polyps. Serrated polyps $\geq 10 \mathrm{~mm}$ have been considered to be an independent risk factor for synchronous AN (OR 3.24, 95\% CI 2.05 to 5.13, $\mathrm{p}<0.0001){ }^{33}$ Patients with at least one large proximal non-dysplastic serrated polyp $(\geq 10 \mathrm{~mm})$ at a screening colonoscopy have been reported to have synchronous AN (OR 3.37, 95\% CI 1.71 to 6.65$).{ }^{12}$ Moreover, large serrated polyps $\geq 10 \mathrm{~mm}$ were at a 2.5 OR risk to develop CRC compared with the population in average risk during an 11-year median follow-up. ${ }^{34}$ Unlike above, the proportions of high-grade dysplasia coexisting with SSA/Ps and TSAs were $0.7 \%$ and $1.0 \%$, respectively, which were much smaller than the proportion coexisting with high-grade dysplasia in conventional adenomas $(5 \%) .{ }^{35}$ The risk of AN formation in patients with proximal serrated polyps $<10 \mathrm{~mm}$ at baseline was consistent with those with low-risk adenoma during surveillance. ${ }^{12}$ The time period required for the progression of SSAs to carcinoma was assumed to be 10-15 years based on a large cohort study including 2139 patients, which concluded that SSAs have a low cancerous progression rate. ${ }^{36}$

Interestingly, Maratt et al ${ }^{37}$ identified several demographic and endoscopic characteristics, including family history of CRC and endoscopist screening ADR, in connexion with the high detection rate of SSA/Ps at baseline. Notably, a recent study found that baseline SA alone might be a risk predictor for the formation of a subsequent large serrated polyp, and synchronous baseline SA and high-risk adenoma put patients at high risk of cancer progression. ${ }^{38}$ Further studies are necessary to determine the contradicting findings.

A meta-analysis found that baseline colonoscopy with excellent bowel preparation and adequate caecal intubation could maximally decrease the risk of interval cancer for identifying missed serrated lesions as efficiently as possible. ${ }^{39}$ Low-quality colonoscopy screening, which has adherent mucus and faecal materials, would contribute to the formation of advanced neoplasia in short follow-up intervals. On the other hand, early AN formation from SA is partly attributed to incomplete resection. Research indicates that the incomplete resection rate of SSA $(30 \%)$ is apparently higher than that of conventional adenoma (10\%) because of its flat shape. ${ }^{1440}$ Fortunately, EMR following contrast injection under a high-definition colonoscope delineates the lesion edges of SAs and allows complete resection. ${ }^{141}$

The limitations of this study should not be ignored. First, the patients with SSAs and those with TSAs were sorted into the same group because of the limited sample size. Further research should be performed to assess the risk rate of progression of adenoma-carcinoma in different subsets of SAs. Second, in a representative cohort of the Caucasoid population including 2416 SSA/Ps in 2139 patients, only 14\% were identified with cytological dysplasia. ${ }^{36}$ In another cohort containing 1910 baseline colonoscopies, only $0.6 \%$ sessile serrated polyp (SSP) had dysplastic histology. ${ }^{42}$ Both dysplastic and non-dysplastic serrated polyps smaller than $10 \mathrm{~mm}$ were included in the procedures. Sessile serrated polyps with cytological dysplasia are more advanced lesions than non-dysplasia serrated polyps, and TSAs are rare with uniform dysplasia. ${ }^{43}$ Larger-scale cohorts are needed to singly determine the optional follow-up intervals for

Main messages

- Patients with serrated adenomas (SAs) $<10 \mathrm{~mm}$ at baseline seemed to have little benefit from follow-up colonoscopy within 5 years after complete polypectomy.

- Patients with a family history of colorectal cancer (CRC) or inadequate baseline colonoscopy need a shorter surveillance interval.

- Age over 50 years, male gender and a history of polyps predict the risk of any subsequent adenoma formation.

Current research questions

- Do patients with serrated adenomas $<10 \mathrm{~mm}$ with dysplasia need to undergo surveillance colonoscopy within a shorter follow-up interval compared with those without cytological dysplasia?

- When should patients with small SA with a family history of CRC undergo follow-up colonoscopy after complete removal?

- What is a better way to identify patients with inadequate baseline colonoscopy? 
SAs $<10 \mathrm{~mm}$ with or without cytological dysplasia. Our research was conducted in a large medical centre. In the future, we will combine our data with several medical centres to further validate our conclusions and strengthen the long-term follow-up of patients with SAs.

Contributors DJ, HC and BW designed the research. DJ, DC, TL, WD and SW collected data. YZ was responsible for pathological analysis. DJ and YQ performed statistical analysis. DJ, BKS and HC wrote the paper. All authors were involved in the final approval of the manuscript.

Funding This study was supported by grants ( 81570478 and 81741075 ) from the National Natural Science Foundation of China, grants (17JCYBJC24900, 15JCZDJC36600) from the Tianjin Research Program of Application Foundation and Advanced Technology of China, and grants (2016BWKY006) from the Research Program of Science and Technology of Tianjin Binhai New Area of Health and Family Planning Commission of China.

Competing interests None declared.

Patient consent for publication Obtained.

Ethics approval The study procedures were approved by the Institutional Review Board of the General Hospital, Tianjin Medical University, China.

Provenance and peer review Not commissioned; externally peer reviewed.

Open access This is an open access article distributed in accordance with the Creative Commons Attribution Non Commercial (CC BY-NC 4.0) license, which permits others to distribute, remix, adapt, build upon this work non-commercially, and license their derivative works on different terms, provided the original work is properly cited, appropriate credit is given, any changes made indicated, and the use is non-commercial. See: http://creativecommons.org/licenses/by-nc/4.0/.

\section{REFERENCES}

1 East JE, Vieth M, Rex DK. Serrated lesions in colorectal cancer screening: detection, resection, pathology and surveillance. Gut 2015;64:991-1000.

2 Pino MS, Chung DC. The chromosomal instability pathway in colon cancer. Gastroenterology 2010;138:2059-72.

3 Giardiello FM, Allen Jl, Axilbund JE, et al. Guidelines on genetic evaluation and management of Lynch syndrome: a consensus statement by the US Multi-society Task Force on colorectal cancer. Am J Gastroenterol 2014;109:1159-79.

4 Jass JR. Classification of colorectal cancer based on correlation of clinical, morphological and molecular features. Histopathology 2007;50:113-30.

5 Andrew AS, Baron JA, Butterly LF, et al. Hyper-methylated loci persisting from sessile serrated polyps to serrated cancers. Int J Mol Sci 2017;18. doi:10.3390/ ijms18030535. [Epub ahead of print: 02 Mar 2017].

6 Chetty R. Traditional serrated adenoma (TSA): morphological questions, queries and quandaries. J Clin Pathol 2016:69:6-11.

7 Rex DK, Ahnen DJ, Baron JA, et al. Serrated lesions of the colorectum: review and recommendations from an expert panel. Am J Gastroenterol 2012;107:1315-29. quiz 1314,1330

8 Chang L-C, Shun C-T, Hsu W-F, et al. Fecal immunochemical test detects sessile serrated adenomas and polyps with a low level of sensitivity. Clin Gastroenterol Hepatol 2017;15:872-9.

9 Pellise M, Burgess NG, Tutticci N, et al. Endoscopic mucosal resection for large serrated lesions in comparison with adenomas: a prospective multicentre study of 2000 lesions. Gut 2017;66:644-53.

10 Repici A, Hassan C, Vitetta E, et al. Safety of cold polypectomy for $<10 \mathrm{~mm}$ polyps at colonoscopy: a prospective multicenter study. Endoscopy 2012:44:27-31.

11 Agarwal A, Garimall S, Scott Fl, et al. En bloc endoscopic mucosal resection is equally effective for sessile serrated polyps and conventional adenomas. Surg Endosc 2018;32.

12 Schreiner MA, Weiss DG, Lieberman DA. Proximal and large hyperplastic and nondysplastic serrated polyps detected by colonoscopy are associated with neoplasia. Gastroenterology 2010;139:1497-502.

13 Nishihara R, Wu K, Lochhead P, et al. Long-term colorectal-cancer incidence and mortality after lower endoscopy. N Engl J Med 2013;369:1095-105.

14 Pohl H, Srivastava A, Bensen SP, et al. Incomplete polyp resection during colonoscopyresults of the complete adenoma resection (CARE) study. Gastroenterology 2013:144:74-80.

15 Kahi CJ, Rex DK. Serrated colorectal neoplasia: from sideshow to center stage. Clin Gastroenterol Hepatol 2017:15:1820-2.

16 Dubé C, Yakubu M, McCurdy BR, et al. Risk of advanced adenoma, colorectal cancer, and colorectal cancer mortality in people with low-risk adenomas at baseline colonoscopy: a systematic review and meta-analysis. Am J Gastroenterol 2017:112:1790-801.

17 van Heijningen E-MB, Lansdorp-Vogelaar I, Steyerberg EW, et al. Adherence to surveillance guidelines after removal of colorectal adenomas: a large, communitybased study. Gut 2015;64:1584-92.

18 Cao H, He N, Song S, et al. Is surveillance colonoscopy necessary for patients with sporadic gastric hyperplastic polyps? PLoS One 2015;10:e0122996.

19 Terdiman JP, McQuaid KR. Surveillance guidelines should be updated to recognize the importance of serrated polyps. Gastroenterology 2010;139:1444-7.

20 Hassan C, Quintero E, Dumonceau J-M, et al. Post-polypectomy colonoscopy surveillance: European Society of Gastrointestinal Endoscopy (ESGE) Guideline. Endoscopy 2013;45:842-51.

21 Valori R, Rey J-F, Atkin WS, et al. European guidelines for quality assurance in colorectal cancer screening and diagnosis. First edition-quality assurance in endoscopy in colorectal cancer screening and diagnosis. Endoscopy 2012;44 Suppl 3(Suppl 3):SE88-105.

22 Lieberman DA, Rex DK. Winawer SJ, et al. Guidelines for colonoscopy surveillance after screening and polypectomy: a consensus update by the US Multi-Society Task Force on Colorectal Cancer. Gastroenterology 2012;143:844-57.

23 East JE, Atkin WS, Bateman AC, et al. British Society of Gastroenterology position statement on serrated polyps in the colon and rectum. Gut 2017;66.

24 Anderson JC, Butterly LF, Robinson CM, et al. Risk of metachronous high-risk adenomas and large serrated polyps in individuals with serrated polyps on index colonoscopy: data from the New Hampshire Colonoscopy Registry. Gastroenterology 2018;154:117-27.

$25 \mathrm{Xu} \mathrm{M}$, Wang S, Cao H, et al. Low rate of advanced adenoma formation during a 5 -year colonoscopy surveillance period after adequate polypectomy of non-advanced adenoma. Colorectal Dis 2016:18:179-86.

26 Vavricka SR, Sulz MC, Degen L, et al. Monitoring colonoscopy withdrawal time significantly improves the adenoma detection rate and the performance of endoscopists. Endoscopy 2016;48:256-62.

27 Calderwood AH, Schroy PC, Lieberman DA, et al. Boston Bowel Preparation Scale scores provide a standardized definition of adequate for describing bowel cleanliness. Gastrointest Endosc 2014;80:269-76

28 Mankaney G, Burke CA. Risk of metachronous advanced neoplasia in patients with diminutive versus small tubular adenomas: is the juice worth the squeeze? Gastrointest Endosc 2017:86:722-3.

29 Okamoto K, Kitamura S, Kimura T, et al. Clinicopathological characteristics of serrated polyps as precursors to colorectal cancer: current status and management. J Gastroenterol Hepatol 2017;32:358-67.

30 Saiki H, Nishida T, Yamamoto M, et al. Frequency of coexistent carcinoma in sessile serrated adenoma/polyps and traditional serrated adenomas removed by endoscopic resection. Endosc Int Open 2016;4:E451-8.

31 Dekker E, IJspeert JEG. Serrated pathway: a paradigm shift in CRC prevention. Gut 2018;67:1751-2

32 Cao H-L, Chen X, Du S-C, et al. Detection rate, distribution, clinical and pathological features of colorectal serrated polyps. Chin Med J 2016;129:2427-33.

33 Li D, Jin C, McCulloch C, et al. Association of large serrated polyps with synchronous advanced colorectal neoplasia. Am J Gastroenterol 2009;104:695-702.

34 Holme Øyvind, Bretthauer M, Eide TJ, et al. Long-term risk of colorectal cancer in individuals with serrated polyps. Gut 2015;64:929-36.

35 Chino A, Yamamoto N, Kato Y, et al. The frequency of early colorectal cancer derived from sessile serrated adenoma/polyps among 1858 serrated polyps from a single institution. Int J Colorectal Dis 2016;31:343-9.

36 Lash RH, Genta RM, Schuler CM. Sessile serrated adenomas: prevalence of dysplasia and carcinoma in 2139 patients. J Clin Pathol 2010;63:681-6.

37 Maratt JK, Dickens J, Schoenfeld PS, et al. Factors associated with surveillance adenoma and sessile serrated polyp detection rates. Dig Dis Sci 2017;62.

38 Anderson JC, Butterly LF, Robinson CM, et al. Risk of metachronous high-risk adenomas and large serrated polyps in individuals with serrated polyps on index colonoscopy: data from the New Hampshire Colonoscopy Registry. Gastroenterology 2018;154.

39 Sulz MC, Kröger A, Prakash M, et al. Meta-analysis of the effect of bowel preparation on adenoma detection: early adenomas affected stronger than advanced adenomas. PLoS One 2016;11:e0154149.

40 Bordaçahar B, Barret M, Terris B, et al. Sessile serrated adenoma: from identification to resection. Dig Liver Dis 2015;47:95-102.

41 Rex KD, Vemulapalli KC, Rex DK. Recurrence rates after EMR of large sessile serrated polyps. Gastrointest Endosc 2015;82:538-41.

42 Abdeljawad K, Vemulapalli KC, Kahi CJ, et al. Sessile serrated polyp prevalence determined by a colonoscopist with a high lesion detection rate and an experienced pathologist. Gastrointest Endosc 2015;81:517-24.

43 Tanaka Y, Yamano H-O, Yamamoto E, et al. Endoscopic and molecular characterization of colorectal sessile serrated adenoma/polyps with cytologic dysplasia. Gastrointest Endosc 2017:86:1131-8. 